University of Nebraska - Lincoln

DigitalCommons@University of Nebraska - Lincoln

8-2004

Child and Adolescent Psychopharmacology in the New

Millennium: A Workshop for Academia, Industry, and Government

Joseph Deveaugh-Geiss

Duke Clinical Research Institute, BRAINSTORMCNS@aol.com

John March

Duke Clinical Research Institute

Mark Shapiro

Duke Clinical Research Institute

Paul J. Andreason

U.S. Food and Drug Administration

Graham Emslie

University of Texas Southwestern Medical Center

See next page for additional authors

Follow this and additional works at: https://digitalcommons.unl.edu/publichealthresources

Deveaugh-Geiss, Joseph; March, John; Shapiro, Mark; Andreason, Paul J.; Emslie, Graham; Ford, Lisa M.; Greenhill, Laurence; Murphy, Dianne; Prentice, Ernest; Roberts, Rosemary; Silva, Susan; Swanson, James M.; Van Zwieten-Boot, Barbara; Vitiello, Benedetto; Dineen Wagner, Karen; and Mangum, Barry, "Child and Adolescent Psychopharmacology in the New Millennium: A Workshop for Academia, Industry, and Government" (2004). Public Health Resources. 292.

https://digitalcommons.unl.edu/publichealthresources/292

This Article is brought to you for free and open access by the Public Health Resources at DigitalCommons@University of Nebraska - Lincoln. It has been accepted for inclusion in Public Health Resources by an authorized administrator of DigitalCommons@University of Nebraska - Lincoln. 


\section{Authors}

Joseph Deveaugh-Geiss, John March, Mark Shapiro, Paul J. Andreason, Graham Emslie, Lisa M. Ford, Laurence Greenhill, Dianne Murphy, Ernest Prentice, Rosemary Roberts, Susan Silva, James M. Swanson, Barbara Van Zwieten-Boot, Benedetto Vitiello, Karen Dineen Wagner, and Barry Mangum 


\title{
Child and Adolescent Psychopharmacology in the New Millennium: A Workshop for Academia, Industry, and Government
}

\author{
JOSEPH DEVEAUGH-GEISS, M.D., JOHN MARCH, M.D., M.P.H., MARK SHAPIRO, M.A., \\ PAUL J. ANDREASON, M.D., GRAHAM EMSLIE, M.D., LISA M. FORD, M.D., \\ LAURENCE GREENHILL, M.D., DIANNE MURPHY, M.D., ERNEST PRENTICE, PH.D., \\ ROSEMARY ROBERTS, M.D., SUSAN SILVA, Ph.D., JAMES M. SWANSON, Pн.D., \\ BARBARA VAN ZWIETEN-BOOT, PH.D., BENEDETTO VITIELLO, M.D., \\ KAREN DiNEEN WAGNER, M.D., Ph.D., ANd BARRY MANGUM, Pharm.D.
}

\begin{abstract}
Objective: To give academic researchers, government officials, and industry scientists an opportunity to assess the state of pediatric psychopharmacology and identify challenges facing professionals in the field. Method: Increased federal spending and the introduction of pediatric exclusivity led to large increases in pediatric psychopharmacology research in the 1990s. Despite the increase in research, concerns exist about methods and incentives for making new medications available for use in pediatric psychiatric disorders. In recognition of these concerns, the Duke Clinical Research Institute held a roundtable in September 2004. Participants from the National Institutes of Health, regulatory agencies, academia, and the pharmaceutical industry spoke about the effects of government regulations such as the U.S. Food and Drug Administration Modernization Act and the Pediatric Research Equity Act on pediatric research from academic, clinical, and industry perspectives, and bioethical considerations of such research. Conclusions: To ensure development of new drugs for treating psychiatric disorders in children and adolescents, we must address the challenges posed by the regulatory environment governing pediatric psychopharmacology research. Strategies were identified for improving the evidence base for psychopharmacologic interventions in youth before widespread use and for more effectively defining a research agenda for the future. J. Am. Acad. Child Adolesc. Psychiatry, 2006;45(3):261-270. Key Words: pediatric psychopharmacology, pediatric depression, psychopharmacology trials, Pediatric Research Equity Act, Best Pharmaceuticals for Children Act.
\end{abstract}

Accepted September 1, 2005.

Drs. DeVeaugh-Geiss, March, Mangum, and Silva, and Mr. Shapiro are with Duke Clinical Research Institute, Durham, NC; Drs. Andreason, Murphy, and Roberts are with the U.S. Food and Drug Administration, Rockville, MD; Dr. Emslie is with the University of Texas Southwestern Medical Center, Dallas; Dr. Ford is with Johnson \& Johnson, Titusville, NJ; Dr. Greenhill is with the New York State Psychiatric Institute, New York; Dr. Prentice is with the University of Nebraska Medical Center, Omaha; Dr. Swanson is with the University of California, Irvine; Dr. van Zwieten-Boot is with the Committee for Medicinal Products for Human Use Medicines Evaluation Board, The Hague, The Netherlands; Dr. Vitiello is with the National Institute of Mental Health, Bethesda, MD; and Dr. Wagner is with the University of Texas Medical Branch, Galveston.

The workshop from which this article derives was supported in part by educational grants from Bristol-Myers Squibb, GlaxoSmithKline, and Johnson
\& Johnson. The following statement is made in accordance with U.S. Food and Drug Administration and National Institute of Mental Health guidelines and may not pertain to all of the authors: The views expressed are those of the authors. No official support or endorsement by the U.S. Food and Drug Administration is provided or should be inferred. No commercial interest or other conflict of interest exists between the authors and the pharmaceutical companies.

Correspondence to Dr. Joseph DeVeaugh-Geiss, Duke Clinical Research Institute, P.O.Box 17969,Durham, NC27715; e-mail:BRAINSTORMCNS@ aol.com.

0890-8567/06/4503-0261@2006 by the American Academy of Child and Adolescent Psychiatry.

DOI: 10.1097/01.chi.0000194568.70912.ee

This article is a U.S. government work, and is not subject to copyright in the United States 
In the past 15 years, efforts by government, academia, and the pharmaceutical industry have yielded numerous advances in pediatric psychopharmacology. Some of the more evident examples of progress include the establishment of infrastructure for pediatric psychopharmacology research (March et al., 2004c; Research Unit on Pediatric Psychopharmacology Anxiety Study Group, 2001), government-funded comparative treatment trials of medications and psychotherapy (March et al., 2004b; MTA Cooperative Group, 1999; Pediatric OCD Treatment Study Team, 2004), U.S. Food and Drug Administration (FDA) approval of attention-deficit/hyperactivity disorder (ADHD) medications developed specifically for children, and regulatory changes designed to encourage psychopharmacology trials in youth, including the FDA Modernization Act (FDAMA), the Best Pharmaceuticals for Children Act (BPCA), the Pediatric Research Equity Act (PREA), and similar legislative efforts outside the United States (Vitiello et al., 2004).

\section{HISTORICAL PERSPECTIVE}

In general, research and practice in child and adolescent psychopharmacology have come on the heels of progress in adult psychopharmacology, with many compounds quickly attaining wide use in children and adolescents despite little or no randomized evidence on which to base clinical practice. Historically, pharmaceutical companies have demonstrated modest interest in developing new psychopharmacological treatments for patients younger than 18 years (Buck, 2000). The exceptions were new formulations of stimulants (methylphenidate and amphetamines) and a nonstimulant (atomoxetine) as treatments for ADHD, and clomipramine and the selective serotonin reuptake inhibitors (SSRIs) as treatments for obsessivecompulsive disorder.

Until the late 1990s, the National Institute of Mental Health (NIMH) funded most of the research in pediatric psychopharmacology, including almost all of the placebo-controlled trials of tricyclic antidepressants and most studies of stimulant medications in ADHD (Vitiello et al., 2004). NIMH funded the first placebo-controlled trial of fluoxetine that showed efficacy in pediatric depression (Emslie et al., 1997), and industry provided support through inves- tigator-initiated research grants but seldom sponsored trials to test the efficacy of medications in children until the mid-1990s, when several companies began to examine stimulants as treatments for ADHD (see Swanson et al., 1998, 1999; Wigal et al., 1998). The pharmaceutical industry's low interest in testing medications in children pertained to most types of medication, not only psychotropic drugs.

\section{EFFECTS OF LEGISLATION AND MARKETING EXCLUSIVITY}

During the mid-1990s, the off-label use of medications in children was widespread enough to spur legislation that, via financial incentives, would accelerate the availability of products licensed for use in children and adolescents without unduly delaying the availability of these products for adults (U.S. Congress, 1997). The legislation, FDAMA's pediatric exclusivity provision, offered 6 months of additional marketing exclusivity (equivalent to extension of patent protection by 6 months) for a drug product in return for the company's conducting pediatric studies on that drug. This powerful incentive changed the landscape of pediatric pharmacology research. Since then, most pediatric clinical trials of psychotropic drugs have been funded by industry, and several pharmacokinetic studies have been completed or are in progress.

The process may be initiated by a sponsor requesting that the FDA issue a Written Request or by the FDA issuing a Written Request of its own volition to the sponsor. By the end of January 2005, 364 requests for pediatric studies $(14 \%$ of these for neuropsychiatric drugs) had been proposed by industry. Of those proposals, the FDA issued Written Requests for 298 products $(13 \%$ of which were for neuropsychiatric drugs; U.S. Food and Drug Administration, 2004c). Thus far, 12 drugs (Adderall XR, Concerta, buspirone, citalopram, venlafaxine, fluvoxamine, paroxetine, fluoxetine, mirtazapine, nefazodone [now withdrawn], atomoxetine, and sertraline) (U.S. Food and Drug Administration, 2000a) used to treat psychiatric disorders in children have been granted additional marketing exclusivity under this program.

Similar regulations are being pursued in Europe that will provide incentives to industry by giving patent-life extension for pediatric medication research. Off-patent products being developed specifically for children will be eligible for a Pediatric Use Marketing 
Authorisation (PUMA) that will ensure 10 years of marketing protection. Although the European Union Commission has agreed on a draft regulation, formal finalization will probably take an additional 1 to 2 years (European Commission, 2004). Furthermore, the International Conference on Harmonisation (ICH) guideline E11, "Clinical Investigation of Medicinal Products in the Pediatric Population," has been agreed on by the three ICH regions: Japan, the United States, and the European Union. Guideline E11 covers general issues, such as the ethics of conducting trials in children, definition of pediatric age groupings, timing of pediatric drug development in relation to drug development in adults, and the possibility for extrapolating efficacy data from adult studies. Moreover, the Committee for Medicinal Products for Human Use and the European Medicines Agency are developing guidelines for the types of trials needed to assess efficacy and safety of medicinal products in children (European Medicines Agency [EMEA] Guidelines, 2000).

\section{SPECIFIC CHALLENGES}

\section{Drug Safety}

Controversies flare up over rare but salient adverse events in the area of child psychopharmacology. Examples include hepatic failure with pemoline treatment (Shevell and Schreiber, 1997), sudden unexplained deaths when methylphenidate and clonidine are used in combination, and suicidality and suicidal ideation during treatment with SSRI and serotoninnorepinephrine reuptake inhibitor (SNRI) antidepressants (U.S. Food and Drug Administration, 2004b). To establish a statistical link between treatment and rare events would require impractical sample sizes, but improved response to these types of controversies is required. New ways are needed to address potential adverse events that are unlikely to be evaluated by traditional clinical trials and statistical approaches. For example, provisions for long-term follow-up (which is expensive) and knowledge of statistical methods for evaluating self-selected groups (e.g., new methods for propensity analyses) are needed to evaluate possible effects that emerge over time or that are the result of early exposure to medication in the sensitive (and vulnerable) pediatric population. Also, some adverse effects, such as those on growth, are important in children but not in adults because individuals who have reached full size cannot experience growth suppression. Long-term follow-up studies are necessary to investigate these potential effects.

\section{Data Ownership}

Although the pediatric exclusivity program launched by FDAMA is considered a success for the number of new studies that it has generated, limitations have emerged. For example, the ownership of data collected during industry-sponsored studies has been an issue; the interpretation has been that such data belong to the sponsor, and it has been the sponsor's decision when - or even whether - to publish. When studies are published, there is often a delay of several years between the approval of a drug and the publication of the clinical trial data upon which that approval is based. The results of many studies are never published, particularly negative SSRI trials in adolescent depression, despite eagerness on the part of academic collaborators to do so. This problem has been corrected, in part, by the BPCA (U.S. Congress, 2002), which mandates the posting of a summary of the medical and clinical pharmacology reviews on the FDA Web site, and through voluntary commitments from industry to make the results of most clinical trials available to the public. Written Requests themselves remain confidential and thus not open to public comment. Furthermore, the academic collaborators are rarely allowed direct access to the data for more complex or alternative analyses.

\section{Timing of Pediatric Studies}

The timing of pediatric studies under FDAMA has also been a complex issue. Written Requests mandate the submission of required pediatric study reports within a specific time frame. Although these requests are designed to provide industry ample time to complete the requested studies, the timelines are considered overly aggressive by some, and further time challenges may be introduced by the internal pressures industry faces when confronting exclusivity or patent expirations. Such time pressures may favor expeditious choices in trial implementation that can affect trial quality or may even dissuade industry from conducting trials altogether. One result of this has been that, in industry-sponsored pediatric psychopharmacology development programs, acute dose pharmacokinetic studies have many times not been completed before initiation of efficacy and safety studies. Without 
appropriate pediatric pharmacokinetic information to guide them, these efficacy and safety trials can meet the requirements of the Written Request but be conducted at doses that are inappropriate for demonstrating efficacy or tolerability in children and in adolescents. Recently, the FDA began requesting that acute pharmacokinetic studies now be completed earlier in the pediatric development cycle, but population pharmacokinetic studies remain rare. Thus, another limitation of FDAMA may be that marketing exclusivity is granted for completing the agreed-on studies, but not necessarily for demonstrating the efficacy or safety of a drug.

After a sponsor has submitted reports in response to a Written Request, the FDA is under a 90-day (in some cases 60-day) statutory constraint to review the submission and determine whether the applicant has fairly responded to the Written Request (i.e., conducted the requested studies). This occurs before the 6-month review of the application is completed. A 6-month period to determine approvability for marketing is mandated under the BPCA for review of the data and information submitted in the pediatric studies. During this period, the quality and meaning of the studies themselves are evaluated, the action on the studies (approval, approvable, nonapproval) is decided, and, ideally, labeling changes are negotiated with the sponsor. Some question whether these time frames allow adequate review. The justification for enacting 6-month review times has been to speed drugs to patients, but because drugs approved for adult use are routinely prescribed to children, this situation does not generally apply in pediatric psychopharmacology. Indeed, the opposite situation prevails: These studies have typically not been completed until years after the medications were made available for adults. Although this is ethically acceptable in cases in which there is already an approved pediatric treatment available, all too often pediatric studies for important treatments are begun late in the drug development process or in response to a Written Request, if at all. As a result, such drugs are often widely prescribed to youth, without evidence of safety or efficacy from controlled studies. Although the incentives provided under the FDAMA have motivated some industry sponsors to conduct additional pediatric studies, the small number of treatment outcome studies in pediatric patients relative to those in adults, the long lag between the time that a drug is introduced for adults and the pediatric trials are conducted, and the fact that pediatric studies are typically conducted in trial populations and with designs that do not match the realities of clinical practices sharply reduce their value to decision makers making choices about patient care.

\section{Insufficient Incentive?}

To justify the investment in research necessary to develop a new drug, industry must carefully assess the size of the potential market for that drug. A recent estimate for the cost of new drug development is $\$ 800$ million (DiMasi et al., 2003). Within pediatric psychopharmacology, the most prevalent disorder is ADHD, which is estimated to affect about $3 \%$ to $5 \%$ of children and adolescents. This prevalence has resulted in a market for the pharmaceutical industry worth $\$ 1.4$ billion/year in 2002 and projected to increase to $\$ 3.3$ billion by 2012 (Garland and Kirkpatrick, 2004). Given that other pediatric mental disorders are less common, they are unlikely to emerge as plausible targets for drug development in their own right because of the high costs of drug development and the significantly smaller prospective market. Thus, exclusivity under the FDAMA and now the BPCA is the primary incentive for industry to study treatments for mental disorders in children and adolescents.

Despite the many studies generated by the FDAMA, only about one third of drugs used in children have pediatric prescribing information in the product label (Roberts et al., 2003). In psychopharmacology, of the 12 products granted exclusivity, the studies resulted in additional indications for just four products: sertraline for pediatric obsessive-compulsive disorder, and Adderall XR, Concerta, and atomoxetine for adolescent ADHD. The latter three were already intended for use in childhood ADHD and the labeling was simply expanded to include use in adolescents. For fluvoxamine and fluoxetine, the studies that resulted in exclusivity and pediatric use indications were initiated before the FDAMA. Otherwise, exclusivity studies of psychopharmacological agents have, for the most part, resulted in labeling language noting that clinical studies did not support a pediatric indication; however, it is important to note that the risk of suicidality associated with antidepressant use in children was first identified from a data set composed primarily of studies done for exclusivity. Thus, it seems that the current systems and incentives are insufficient to ensure that psychopharmacological drug products will be developed for 
children and adolescents even when those drugs are intended to be marketed for adult use.

Complicating this situation is the fact that some of the drugs that are effective in adult disorders (antidepressants being the most studied) do not appear to have the same efficacy in children. Whether this is because childhood disorders are somehow different from the adult versions, because placebo or nonspecific responses are different in children (making it harder to discriminate drug effect), or because the immature CNS responds differently to pharmacological influences, the result is that many pediatric clinical trials conducted for the purpose of gaining additional marketing exclusivity are not providing clinicians with data that support the use of these drugs in their pediatric and adolescent patients. If there are pharmacological treatments that are effective mainly in the pediatric but not the adult population, what can be done to increase the likelihood that the pharmaceutical industry will want to develop them? Can we find another system for promoting the discovery of drugs that are effective in this population?

\section{RECOMMENDATIONS}

Greater emphasis must be placed on safety outcomes, such as through the use of standardized safety assessment tools and long-term studies. Greenhill et al. (2004) recently reported that the body-systems review method used in the Safety Monitoring Uniform Report Form can, by focusing on individual organs, help detect additional medically important adverse events missed by the methods typically used in industry trials, such as the spontaneous reporting or general inquiry elicitation methods. Moreover, standardized methods of collecting safety data could facilitate pooling of data from multiple clinical development programs, enabling safety assessments, such as one conducted by the FDA in 2004 evaluating selfharm in children and adolescents treated with antidepressant drugs, to provide the sample size needed to detect uncommon adverse events (Vitiello et al., 2003). In addition, because some side effects, such as attenuation of growth, are important in children but not in adults (because adults have reached full stature, they cannot show growth suppression), longterm studies are needed to evaluate possible effects that emerge over time or are caused by early exposure to medication during development.

\section{Practical Clinical Trial Networks}

In addition to establishing efficacy, future studies ideally should provide long-term evidence of safety in children and adolescents and also include relevant populations in terms of comorbidities and concurrent medications. However, typical efficacy studies, which exclude most comorbidity, are relatively brief and are too small to identify subgrouping variables or other than common adverse events. Large, simple effectiveness trials conducted on practical clinical trial (PCT) networks offer a platform on which to deploy standardized adverse event reporting measures, allow identification of moderators of treatment outcome, and can be used to establish safety databases to define the risks and tolerability of drugs during short- and long-term treatment in the pediatric population.

PCTs are typically characterized by eight key features: a straightforward, clinically relevant question, a representative sample of patients and practice settings, sufficient power to identify modest but clinically relevant effects, randomization to protect against bias, clinical uncertainty regarding the outcome of treatment at the patient level, assessment and treatment protocols that employ best clinical practices, simple and clinically relevant outcomes, and limited subject and investigator burden (March et al., 2005). Implementing the PCT model in psychiatry will require construction of a stable network of clinical investigators as well as methodological innovation in assessment, treatment, data management, site management, and data analytic procedures. One example of the PCT model is the Child and Adolescent Psychiatry Trials Network, which is funded by the $\mathrm{NIMH}$ and is a collaborative effort of the Duke Clinical Research Institute and the American Academy of Child and Adolescent Psychiatry (March et al., 2004c).

PCTs can also help satisfy the need for improved drug safety assessments by supplementing pharmacoepidemiological studies of large naturalistic databases, such as those collected and maintained by the FDA and health maintenance organizations. Passive surveillance, such as FDA's MedWatch reporting system and the Adverse Event Reporting System database, although suitable for detecting rare events that are severe and unexpected, may not be suitable for detecting drug effects for commonly reported adverse events. In addition, passive reporting systems do not estimate the event incidence rate relative to control or active comparators, which benefit from systematic adverse 
events assessments (Greenhill et al., 2004). Health maintenance organizations, Medicaid, and databases such as the General Practice Research Database offer the possibility of longitudinal assessments that allow for the testing of specific hypotheses (Rodriguez et al., 2001). In pediatric psychopharmacology, the General Practice Research Database has recently been used to examine the relationship between suicidal behavior and antidepressant treatment (Jick et al., 2004).

\section{Risk-Benefit and Placebo-Controlled Trials}

As the pediatric psychopharmacology field has become more prominent, so have issues involving the ethical context in which trials are conducted (Derivan et al., 2004; March et al., 2004a). For example, 21 CFR 50, Subpart D, has extended the protections afforded to children in federally sponsored clinical trials (first codified in 45 CFR 46, Subpart D) to all clinical trials involving FDA-regulated products. Subpart D contains four categories of research based on the degree of risk (i.e., minimal or greater than minimal) and whether there is the prospect of direct subject benefit. Most clinical trials involving children are classified under 21 CFR 50.52, which is research involving greater than minimal risk but presenting a prospect of direct benefit to the individual subjects. Under Section 50.52, an institutional review board must determine that the risk-benefit relationship of the research is at least as favorable to the subjects as that presented by available therapeutic alternatives. Such research must be in clinical equipoise - that is, there must be genuine uncertainty on the part of the expert medical community as to the comparative therapeutic merits of each arm of the clinical trial.

Achievement of clinical equipoise can be particularly problematic in placebo-controlled, randomized controlled trials (RCTs; Derivan et al., 2004; March et al., 2004a). In pediatric research, the risk-benefit relationship must be at least as favorable as that of alternative treatments (Section 50.52). Therefore, investigators and institutional review boards must justify placebo controls with consideration of direct subject benefit and available alternatives. If a pediatric study cannot meet the requirements of Section 50.52, then it must be considered under additional Subpart D categories, which contain more stringent approval requirements.

Clearly, the ethical basis for conducting research in children is different from that for adults and remains an evolving process (Fost, 2001; Greenhill et al., 2003). Recent trends point to increasingly restrictive elements, which will make the use of placebo exceedingly difficult, thus potentially limiting the number of drug candidates that can be adequately studied. For example, under the most restrictive assumptions, once the first drug in a class is shown to be superior to placebo, it could be nearly impossible to conduct similar trials with additional drugs from that class; indeed, once any effective treatment has been shown for a given condition, it may become difficult to study any other treatments for that condition. At the same time, it is important to recognize the value of a placebo arm in a clinical study evaluating the safety of an investigational drug. Thus, reasonable voices argue that properly designed placebo-controlled trials remain necessary, ethical, and feasible but may require innovative research designs; greater involvement of consumers in planning and implementing research; flexibility by industry, academia, the National Institutes of Health, and regulatory agencies to act in partnership; and, where needed, concomitant use of evidence-based psychosocial services (March et al., 2004).

\section{Alternatives to Classic RCTs?}

Although the classic placebo-controlled RCT appears to be increasingly more difficult to conduct in this population for reasons of ethics and feasibility, the implementation of the BPCA (U.S. Congress, 2002) and PREA (U.S. Congress, 2003) will result in more placebo-controlled RCTs in children and adolescents. Because Subpart D was not written with any focus on placebo controls, justification of placebo control will require collaboration of investigators and institutional review boards to use placebo when it is scientifically, medically, and ethically justified (Derivan et al., 2004; March et al., 2004).

In addition, before effectiveness trials on PCT networks, placebo-controlled efficacy studies emphasizing mechanisms of treatment response may be required to optimize the use of medication, even those with long clinical histories, as recent examples from the pharmacokinetic/pharmacodynamic studies of stimulant medication have demonstrated. This approach characterized the development of most of the new formulations of stimulants for the treatment of ADHD, with concept studies based on highly controlled trials using the Laboratory School Paradigm and surrogate measures 
of efficacy, before large, randomized clinical trials to demonstrate efficacy and gain FDA approval were conducted. In the area of stimulants, small comparison trials are being conducted to distinguish the many new formulations (Concerta versus Metadate; Swanson et al., 2004) and classes of medications (Adderall XR versus atomoxetine) in tightly controlled experimental designs funded by industry. Head-to-head trials of these medications in large, real-world samples have yet to be conducted, and, as a result, clinical decision makers cannot be sure of their relative value and who benefits or has unacceptable adverse events. Hence, there is a need for large PCTs comparing the new psychostimulant preparations and also the new nonstimulant atomoxetine, perhaps to older-generation immediate-release stimulant preparations.

In some cases, child and adolescent psychopharmacology researchers may need to employ alternatives to the classic RCT that has been the standard for psychopharmacology drug development for nearly 50 years. Alternative designs may include active controlled noninferiority (or superiority) trials, adaptive designs, group sequential designs, patient preference designs, and equipoise-stratified designs. Moreover, although psychopharmacology research (particularly in the development of new drugs) has historically either excluded or limited psychotherapy during a trial, the role of behavioral and other approaches in pediatric practice must be evaluated alone and in combination with medications (Franklin et al., 2003; Treatment for Adolescents With Depression Study Team, 2003). If behavioral interventions can influence the effects of drug treatment, then this could have important implications for both the efficacy and safety of drug treatment. Considering the numerous failures (particularly with antidepressant drugs) to show benefits of drug treatment alone in this population, we must be open to studying other approaches.

\section{CONCLUSIONS}

Historically, the pharmaceutical industry and academia have not shared an agenda for research in children and adolescents. Despite the legislative changes of the past 8 years, which have resulted in an obvious interest on the part of industry, the academic and industry research agendas in pediatric psychopharmacology are poorly aligned. The most likely cause for this is that the two enterprises are working toward different objectives. Industry, whose agenda is driven by the desire to meet regulatory requirements to include information in the drug label, focuses on meeting the FDA's issuance of Written Requests, which have called for RCTs of widely used medications versus placebo, in relatively homogeneous populations, for single disorders, and powered to test for efficacy rather than safety. Having first established efficacy where appropriate, clinical decision makers are seeking active comparator and treatment addition trials in trial populations that resemble real-world clinical practice. A more satisfactory approach may be for industry and academia to partner with the FDA to pursue Written Requests that meet the needs of clinical decision makers as well as satisfy the FDA's desire for placebocontrolled designs.

The dialogue between these parties needs to be more focused on the needs of children and adolescents as well as those who treat them. Although no one would expect the pharmaceutical industry to pursue a research agenda contrary to the interests of its shareholders, the incentives that are currently in place have thus far been insufficient to improve the pharmacological treatment of children and adolescents with psychiatric disorders in a meaningful way. This could be rectified by establishing a forum wherein the needs of this patient population are clearly articulated in the strategic thinking of those defining the research agenda for industry. Ideally, incentives would exist within the industry to pursue the child and adolescent population as a strategic target in and of itself. Although academic experts will continue to rely heavily on industry for funding, mechanisms are needed whereby that reliance does not further tilt the academic agenda toward the industry agenda or create real or apparent conflicts of interest. In addition, academic experts who accept financial support from industry must maintain their own integrity and protect the credibility of the academic enterprise.

Communication has been a challenge not only between academia and industry but also among pediatric psychopharmacologists. Although the pediatric psychopharmacology research community is not large, there appears to be difficulty in exchanging ideas adequately within the field, and even less systematization is in place to disseminate new knowledge. Interaction between child and adolescent psychiatry with the broader field of pediatrics is also limited, although 
pediatricians increasingly treat mentally ill youths with psychotropic medications. Moreover, child and adolescent psychiatry has been rather unsuccessful in its communication with the public, despite the existence of patient- and consumer-oriented organizations with sincere commitments to the welfare of the child and adolescent population. The recent controversy surrounding the use of antidepressant drugs in this patient population highlights these difficulties.

Better communication strategies are needed. There have been many meetings of stakeholders since the early 1990s (see, e.g., March et al., 2005). Although these meetings have helped move the field forward to some degree, there is a general sense that the momentum is weak. More dialogue is needed, both within the child and adolescent psychiatry community, as well as with pediatrics and primary care. Direct involvement of patients and their families in psychopharmacology research, in ways other than as research subjects, will enhance the dissemination of information to the public. It is suggested that patient representatives be included in the process of study design and in some way participate in the evaluation of data, perhaps through a relationship to data and safety monitoring boards. A stronger voice for pediatrics that crosses therapeutic areas and is to some extent separate from adult drug development programs within the pharmaceutical industry would be desirable.

The research agenda is itself uncertain. For example, the landscape of mental health services is changing rapidly (Safer, 1997). More children are receiving drug treatments (see, e.g., Zito et al., 1999, 2000) and fewer receive psychosocial treatments (Hoagwood et al., 2000). It is usually assumed but not proven that higher quality, evidence-based treatments delivered by providers who are current with respect to best practice standards would result in improved mental health outcomes (Guyatt et al., 2000; Weisz and Hawley, 1998). In this context, informed observers agree that there is a conspicuous and unfortunate gap between research and practice that reflects considerable heterogeneity in the type and quality of care delivered to mentally ill youths (Szatmari, 1999). This gap provides both the rationale and, in some sense, the method for advancing a pragmatic clinical trials agenda. Although clinician opinion and data from efficacy trials, pharmacoepidemiology, and treatment guidelines highlight gaps in the evidence base, there appears to be no mechanism for deciding which questions to ask and with what priority to pursue them. To some extent, this concern is a consequence of the communication and industry-academia alliance problems noted above; at the least, they overlap considerably.

The agenda needs to be defined through a collaborative process that includes and addresses the needs of all stakeholders (clinicians, patients, and families, academic researchers, industry, and government). A mechanism is needed for deciding and prioritizing the questions. One effective mechanism would be to convene a National Institutes of Health Consensus Development Conference, as was done in 1995, to explore these issues and to help define the research agenda (Vitiello and Jensen, 1997). To be effective globally, however, such a conference needs to have international participation consistent with the spirit and intent of $\mathrm{ICH}$.

For drugs being developed for adults, the pediatric studies should occur much earlier in the development cycle and should include more than the minimalist approach that has been followed under current regulatory incentives. Incentives for conducting pediatric studies could be revised to reward efforts that produce useful information about safety and efficacy that can actually guide practice. Ideally, the pediatric population would be viewed by the pharmaceutical industry as a target population, much like the targets currently recognized as therapeutic areas, and drugs would be developed for children by first intent. Some drugs could be developed for pediatric use, although others may be for both pediatric and adult use, and still others for use in adults only.

The use of psychotropic medicines in children continues to increase faster than the evidence base supporting such use. Yet, child and adolescent pharmacology has made significant advances in the past 15 years. In part, this is the result of regulatory incentives provided to the pharmaceutical industry, although careful assessment of these incentives reveals a number of shortcomings. These shortcomings have resulted in research that is less valuable to clinicians treating mentally ill youths than to other stakeholders. This situation, coupled with insufficient communication within the pediatric psychopharmacology community and with the public, has led to several controversies in recent years. In the future, the research enterprise in child and adolescent psychiatry will need to improve 
communications and focus on better meeting the needs of pediatric and adolescent patients through improved or refined regulatory incentives, greater attention to drug safety, and development of innovative clinical trial designs and methods.

Disclosure: Dr. DeVeaugh-Geiss is a consultant to Voyager Pharmaceutical Corp., Vela Pharmaceuticals, and Neurotherapeutics Pharma (and previously to GlaxoSmithKline, Elan, Schwarz Pharma, Ceregene, and Pozen); is on the board of directors of Vela Pharmaceuticals; is a major shareholder in GlaxoSmithKline; and owns shares in Voyager Pharmaceutical Corp. and Pozen. Dr. March is or has been a consultant or scientific adviser to Pfizer, Wyeth, Lilly, and Jazz Pharmaceuticals; has received research support andlor study drugs from Pfizer and Lilly; has served on data safety monitoring boards for Organon, AstraZeneca, and Johnson \& Johnson, and receives royalties from the Multidimensional Anxiety Scale for Children. Dr. Emslie has research grants from andlor consultancies with Eli Lilly, Organon, Forest Laboratories, GlaxoSmithKline, Pfizer, and Wyeth-Ayerst and is on the speaker's bureau of $M c N e i l$. Dr. Greenhill receives research grant support from Novartis, Lilly, and Otsuka and has consultancies with Wyeth, Lilly, and Novartis. Dr. Swanson has consultancies with andlor honoraria from McNeil, Shire, Cephalon, Novartis, CellTech, Eli Lilly, and Janssen Pharmaceutica. Dr. Wagner receives research support from Eli Lilly and Organon and is a consultant to Abbott Laboratories, Bristol-Myers Squibb, Eli Lilly, Forest Laboratories, GlaxoSmithKline, Janssen Pharmaceutica, Jazz Pharmaceuticals, Novartis, Ortho-McNeil, Otsuka, and Pfizer. The other authors have no financial relationships to disclose.

\section{REFERENCES}

Buck ML (2000), The FDA Modernization Act of 1997: impact on pediatric medicine. Pediatr Pharmacother 6:12

Derivan AT, Leventhal BL, March J, Wolraich M, Zito JM (2004), The ethical use of placebo in clinical trials involving children.J Child Adolesc Psychopharmacol 14:169-174

DiMasi JA, Hansen RW, Grabowski HG (2003), The price of innovation: new estimates of drug development costs. J Health Econ 22:151-185

Emslie GJ, Rush AJ, Weinberg WA et al. (1997), A double-blind, randomized, placebo-controlled trial of fluoxetine in children and adolescents with depression. Arch Gen Psychiatry 54:1031-1037

European Commission (2004), Draft regulation; http://pharmacos.eudra.org/ f2/paediatrics/index.htm. Accessed October 7, 2005

European Medicines Agency (EMEA) 2000 Guidelines; http://www.emea.eu. int/pdfs/human/ich/271199en. Accessed May 11, 2005

Fost N (2001), Ethical issues in research and innovative therapy in children with mood disorders. Biol Psychiatry 49:1015-1022

Franklin M, Foa E, March JS (2003), The Pediatric Obsessive-Compulsive Disorder Treatment Study: rationale, design, and methods. J Child Adolesc Psychopharmacol 13:S39-S51

Garland M, Kirkpatrick P (2004), Atomoxetine hydrochloride. Nat Rev Drug Discov 3:385-386

Greenhill LL, Vitiello B, Abikoff H et al. (2003), Developing methodologies for monitoring long-term safety of psychotropic medications in children: report on the NIMH conference, September 25, 2000. J Am Acad Child Adolesc Psychiatry 42:651-655

Greenhill LL, Vitiello B, Fisher P et al. (2004), Comparison of increasingly detailed elicitation methods for the assessment of adverse events in pediatric psychopharmacology. J Am Acad Child Adolesc Psychiatry 43: $1488-1496$

Guyatt GH, Meade MO, Jaeschke RZ, Cook DJ, Haynes RB (2000), Practitioners of evidence based care. Not all clinicians need to appraise evidence from scratch but all need some skills [editorial]. BMJ 320:954-955
Hoagwood K, Kelleher KJ, Feil M, Comer DM (2000), Treatment services for children with ADHD: a national perspective. J Am Acad Child Adolesc Psychiatry 39:198-206

Jick H, Kaye JA, Jick SS (2004), Antidepressants and the risk of suicidal behaviors. JAMA 292:338-343

March J, Kratochvil C, Clarke G et al. (2004a), AACAP 2002 research forum: placebo and alternatives to placebo in randomized controlled trials in pediatric psychopharmacology. I Am Acad Child Adolesc Psychiatry 43:1046-1056

March J, Silva S, Petrycki S et al. (2004b), Fluoxetine, cognitive-behavioral therapy, and their combination for adolescents with depression: Treatment for Adolescents With Depression Study (TADS) randomized controlled trial. JAMA 292:807-820

March JS, Silva SG, Compton S et al. (2004c), The Child and Adolescent Psychiatry Trials Network (CAPTN). J Am Acad Child Adolesc Psychiatry 43:515-518

March JS, Silva SG, Compton S, Shapiro M, Califf R, Krishnan R (2005), The case for practical clinical trials in psychiatry. Am J Psychiatry 162:836-846

MTA Cooperative Group (1999), A 14-month randomized clinical trial of treatment strategies for attention-deficit/hyperactivity disorder. Multimodal Treatment Study of Children with ADHD. Arch Gen Psychiatry 56:1073-1086

Pediatric OCD Treatment Study Team (2004), Cognitive-behavior therapy, sertraline, and their combination for children and adolescents with obsessive-compulsive disorder: the Pediatric OCD Treatment Study (POTS) randomized controlled trial. JAMA 292:1969-1976

Research Unit on Pediatric Psychopharmacology Anxiety Study Group (2001), Fluvoxamine for the treatment of anxiety disorders in children and adolescents. N Engl J Med 344:1279-1285

Roberts R, Rodriguez W, Murphy D, Crescenzi T (2003), Pediatric drug labeling: improving the safety and efficacy of pediatric therapies. JAMA 290:905-911

Rodriguez EM, Staffa JA, Graham DJ (2001), The role of databases in drug postmarketing surveillance. Pharmacoepidemiol Drug Saf 10:407-410

Safer DJ (1997), Changing patterns of psychotropic medications prescribed by child psychiatrists in the 1990s. J Child Adolesc Psychopharmacol 7:267-274

Shevell M, Schreiber R (1997), Pemoline-associated hepatic failure: a critical analysis of the literature. Pediatr Neurol 16:14-16

Swanson J, Gupta S, Guinta D et al. (1999), Acute tolerance to methylphenidate in the treatment of attention deficit hyperactivity disorder in children. Clin Pharmacol Ther 66:295-305

Swanson JM, Wigal SB, Udrea D et al. (1998), Evaluation of individual subjects in the analog classroom setting: I. Examples of graphical and statistical procedures for within-subject ranking of responses to different delivery patterns of methylphenidate. Psychopharmacol Bull 34:825-832

Swanson JM, Wigal SB, Wigal T et al. (2004), A comparison of once-daily extended-release methylphenidate formulations in children with attentiondeficit/hyperactivity disorder in the laboratory school (the COMACS Study). Pediatrics 113:206-216

Szatmari P (1999), Evidence-based child psychiatry and the two solitudes. Evid Based Ment Health 2:6-7

Treatment for Adolescents With Depression Study Team (2003), Treatment for Adolescents With Depression Study (TADS): rationale, design, and methods. J Am Acad Child Adolesc Psychiatry 42:531-542

U.S. Congress (1997), Food and Drug Administration Modernization Act of 1997 (FDAMA). Public Law 105-115

U.S. Congress (2002), Best Pharmaceuticals for Children Act (BPCA). Public Law 107-109

U.S. Congress (2003), Pediatric Research Equity Act of 2003 (PREA). Public Law 108-155

U.S. Food and Drug Administration (2004a), http://www.fda.gov/cder/ pediatriclexgrant.htm. Accessed May 11, 2005

U.S. Food and Drug Administration (2004b), http://www.fda.gov/bbs/topics/ news/2004/new01124.html. Accessed May 11, 2005

U.S. Food and Drug Administration (2004c), Approved moieties to which FDA has issued a written request for pediatric studies under section 505A of the Federal Food, Drug, and Cosmetic Act; http://www.fda.gov/cder/ 
pediatric/wrstats.htm, last updated February 28, 2005. Accessed May 11, 2005

Vitiello B, Heiligenstein JH, Riddle MA, Greenhill LL, Fegert JM (2004), The interface between publicly funded and industry-funded research in pediatric psychopharmacology: opportunities for integration and collaboration. Biol Psychiatry 56:3-9

Vitiello B, Jensen PS (1997), Medication development and testing in children and adolescents. Current problems, future directions. Arch Gen Psychiatry 54:871-876

Vitiello B, Riddle MA, Greenhill LL et al. (2003), How can we improve the assessment of safety in child and adolescent psychopharmacology? J Am Acad Child Adolesc Psychiatry 42:634-641
Weisz JR, Hawley KM (1998), Finding, evaluating, refining, and applying empirically supported treatments for children and adolescents. J Clin Child Psychol 27:206-216

Wigal SB, Swanson JM, Greenhill L et al. (1998), Evaluation of individual subjects in the analog classroom setting: II. Effects of dose of amphetamine (Adderall). Psychopharmacol Bull 34:833-838

Zito JM, Safer DJ, dosReis S, Gardner JF, Boles M, Lynch F (2000), Trends in the prescribing of psychotropic medications to preschoolers. JAMAo 283:1025-1030

Zito JM, Safer DJ, dosReis S, Magder LS, Gardner JF, Zarin DA (1999), Psychotherapeutic medication patterns for youths with attention-deficit/ hyperactivity disorder. Arch Pediatr Adolesc Med 153:1257-1263 